\title{
A controlled trial of a regularly cycled oscillating waterbed and a non-oscillating waterbed in the prevention of apnoea in the preterm infant
}

\author{
ROSAMOND A K JONES \\ Department of Paediatrics and Neonatal Medicine, Hammersmith Hospital, London
}

SUMMARY Fourteen preterm infants spent a mean of 23 hours divided into 4-hour periods with and without regular oscillations, 10 infants also being studied for control periods, before and afterwards. Electrocardiogram and impedance pneumogram were recorded continuously and analysed blindly. The waterbed, with or without oscillations, had no effect on apnoea or bradycardia when compared with control periods. Infants had appreciably more episodes of severe bradycardia while on the oscillating than on the non-oscillating waterbed.

In 1975 , Korner et al. $^{1}$ reported that waterbed flotation reduced apnoea in preterm infants. They used a water-filled mattress with irregular head-tofoot oscillations at 12 to 14 per minute, hoping to enhance behavioural maturation by giving vestibuloproprioceptive stimulation as in utero. Ten infants randomly assigned to the waterbed unexpectedly had fewer apnoeic episodes than did controls. The same authors confirmed these results in 8 infants with recurrent apnoea, studied on and off the mattress. ${ }^{2}$ The present study aimed to see if similar benefit was obtained using a waterbed without oscillations or one with a regular cycle.

\section{Method}

Patients. Infants of 32 weeks' gestation or less admitted to the neonatal intensive care unit at Hammersmith Hospital from September 1979 to June 1980 were eligible for the study, which was approved by the Ethical Committee. Infants with major congenital abnormality or clinical evidence of central nervous system disease were excluded, but those with respiratory distress were studied after recovery. Infants with recurrent apnoea of prematurity (defined as $\geqslant 10$ seconds' apnoea with bradycardia $<100 /$ minute or cyanosis at least 3 times in 24 hours) were treated with theophylline before starting the waterbed investigation.

Informed parental consent was obtained. Fourteen infants were studied, 11 with mild (less than 3 episodes per day) or no clinically recognised apnoea, and 3 infants with severe apnoea studied after starting theophylline (all 3 had stable blood theophylline levels throughout the investigation). Gestation ranged from 27.0 to 32.6 (median 29.4) weeks, birthweight from 930 to 1470 (median 1080) g, and postnatal age from 1 to 32 (median 8 ) days.

Procedure. The waterbed used was similar to that described by Korner et al. ${ }^{12}$ with an inflatable bladder placed under the head end. This could be connected to a ventilator pumping regularly at 12 to 14 cycles per minute, to produce an oscillation of only 1 to $2 \mathrm{~mm}$ amplitude at the mattress surface when no infant was in place, but visibly moving the resting infant. Infants spent a mean of 23 hours on the waterbed divided into 4-hour periods with and without oscillations, in random order. Ten of the infants were studied for a further 11 hours with the mattress emptied of water, divided between the beginning, middle, and end of the time on the waterbed. Electrocardiogram and impedance pneumogram were recorded continuously on to cassette tapes (Infant Monitor by Healthdyne Inc. adapted with cassette recorder by Oxford Medical Systems), and later printed on to paper through a replay unit by Oxford Medical Systems and a Mingograph Chart Recorder (Siemens Ltd).

Tapes had code numbers and were analysed by me without knowing the patient or treatment. Strict criteria for distinguishing apnoea from shallow respiration were used (details available from the author). The duration of each apnoeic episode and each bradycardia was measured and the time noted and the hourly rates on each 'treatment' subsequently calculated. The percentages of recording time spent apnoeic and with a heart rate of 80 or below were also calculated. Using each infant as his own control, the differences were calculated between treatments and then compared by paired $t$ test or Wilcoxon's signed rank sum test as appropriate.

\section{Results}

Table 1 shows the results for 14 babies on the waterbed comparing periods with or without regular oscillation. There was no appreciable difference in apnoeic episodes of 3 to 9 seconds' 
duration nor was there any difference in bradycardia of 80 or below. Only 6 infants had apnoeic attacks of 10 seconds or more, and in 5 these were more frequent on the oscillating bed. Eleven infants suffered severe bradycardia of 60 or less per minute and these episodes were significantly more frequent during periods of regular oscillation.

Table 2 shows results for the 10 infants in whom a control period with the waterbed emptied was recorded. None of the parameters measured showed

Table 1 Comparison of the waterbed with and without oscillations $(n=14)$

\begin{tabular}{|c|c|c|}
\hline & $\begin{array}{l}\text { Oscillating } \\
\text { bed minus } \\
\text { non-oscillating bed } \\
\text { (mean } \pm S D)\end{array}$ & $P^{*}($ paired $t$ test $)$ \\
\hline \multicolumn{3}{|l|}{ Apnoea } \\
\hline hourly rate & $+0.46 \pm 1.14$ & $>0.1$ \\
\hline $\begin{array}{l}\text { *Apnoea } \\
\geqslant 10 \text { seconds } \\
\text { hourly rate }\end{array}$ & $\begin{array}{l}+0.13^{* *} \\
(-0.01 \text { to }+0.31)\end{array}$ & $>0 \cdot 1^{* *}$ \\
\hline$\%$ time apnoeic & $+0.08 \pm 0.16$ & $0.05<\mathrm{P}<0.1$ \\
\hline $\begin{array}{l}\text { Longest apnoea } \\
\text { (seconds) }\end{array}$ & $+2.6 \pm 6.9$ & $>0.1$ \\
\hline $\begin{array}{l}\text { Bradycardia } \\
\leqslant 80 / \mathrm{min}, \\
\text { hourly rate }\end{array}$ & $+0.08 \pm 0.35$ & $>0.1$ \\
\hline $\begin{array}{l}\% \text { time with } \\
\text { heart rate } \\
\leqslant 80 / \mathrm{min}\end{array}$ & & \\
\hline $\begin{array}{c}\text { ***Bradycardia } \\
\leqslant 60 / \mathrm{min}, \\
\text { hourly rate }\end{array}$ & $+0.06 \pm 0.25$ & $<0.02$ \\
\hline $\begin{array}{l}\text { Slowest heart rate, } \\
\text { beats } / \mathrm{min} \text {. }\end{array}$ & $-4 \cdot 6 \pm 6 \cdot 4$ & $<0.02$ \\
\hline
\end{tabular}

*8 infants excluded had no apnoea $\geqslant 10$ seconds, that is $n=6$. ** Differences expressed as median and range: Wilcoxon's signed rank sum test (differences not normally distributed).

*** 3 infants excluded had no bradycardia $\leqslant 60 / \mathrm{min}$-that is $n=11$.

Table 2 Comparison of the non-oscillating waterbed and the oscillating waterbed with the control periods $(n=10)$

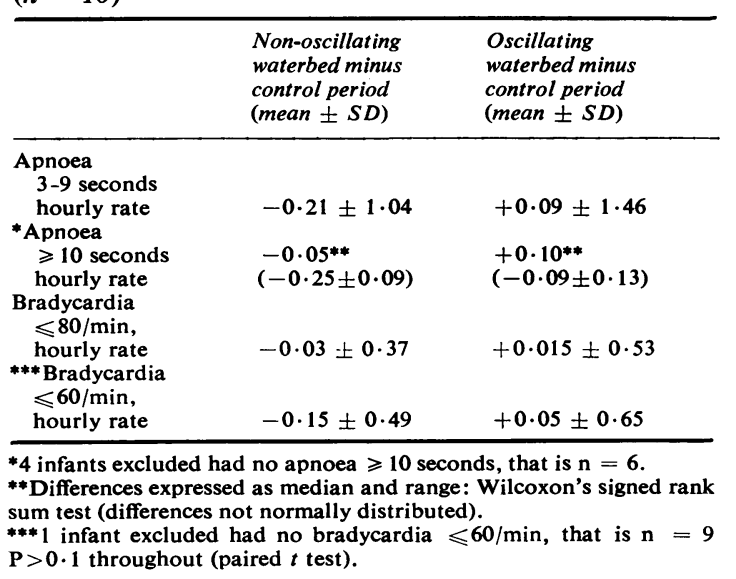

any significant difference between periods spent on or off the waterbed. Response to the waterbed appeared unaffected by maturity of the infants, severity of the apnoea, or use of theophylline.

Side effects. Mean body temperature while on the waterbed was $0 \cdot 1{ }^{\circ} \mathrm{C}$ lower than in the previous 24 hours (Wilcoxon's signed rank sum test, $P<0 \cdot 01$ ). The drop in temperature was generally slight, but one baby developed hypothermia of $35 \cdot 2^{\circ} \mathrm{C}$, persisting until the waterbed was removed, and a further 6 infants required an increase in the incubator setting in order to maintain their body temperatures. No increase in vomiting occurred.

\section{Discussion}

Recurrent apnoea in the preterm infant has a high mortality and morbidity. Treatment with xanthines or continuous positive airways pressure may be effective, ${ }^{34}$ but both have potential side effects. Cutaneous stimulation has also been shown to be effective, but is costly on nursing time. The possibility that a rocking waterbed may prevent attacks is thus very appealing. In Korner's study, ${ }^{12}$ an irregular cycle was deliberately chosen to mimic maternal respirations. The mechanism of the beneficial effect on apnoea is uncertain but they found a significant reduction in indeterminate sleep with waterbed use, and it was in this sleep state that $\rightleftharpoons$ apnoea and bradycardia were reduced. ${ }^{2}$

At the time of our study, no neonatal rocking waterbed was available commercially in the UK. However, a water-tight bag was easily made, and use of an outmoded ventilator allowed regular oscillations. The lack of demonstrable benefit from the non-oscillating or regularly oscillating waterbed compared with the control period was disappointing. The slight drop in body temperature associated with the use of the waterbed might have been expected to reduce apnoea. ${ }^{5}$ Before waterbeds enter widespread use, attention must be paid to temperature control and also to precautions against bacterial contamination and leakage.

Our findings suggest that a regularly-cycled (12-14/minute) rocking waterbed may even be detrimental compared with a non-oscillating waterbed. Kramer and Pierpoint, ${ }^{6}$ using a waterbed rocked regularly at 25 to 30 cycles per minute plus auditory stimulation in a group of preterm infants, showed enhanced growth compared with controls, but did not mention the effect on apnoea.

Further study is needed to establish the exact benefits of waterbeds and to determine the optimum rhythm and rate for promoting growth and reducing apnoea. 
I thank Dr David Southall for use of equipment for analysing the tapes, Professor M Healy for help with statistics, Dr Pamela Davies for advice throughout the study, and the parents and infants.

This work was generously supported by Action Research for the Crippled Child. Water mattresses were donated by Flotronaire Limited and cassette tapes by Sony Limited.

\section{References}

1 Korner A F, Kraemer H C, Haffner M E, Cosper L M. Effects of waterbed flotation on premature infants: a pilot study. Pediatrics 1975 ; 56: 361-7.

2 Korner A F, Guilleminault C, Van den Hoed J, Baldwin R B. Reduction of sleep apnea and bradycardia in preterm infants on oscillating waterbeds: a controlled polygraphic study. Pediatrics $1978 ; 61$ : 528-33.
3 Kuzemko J A, Paala J. Apnoeic attacks in the newborn treated with aminophylline. Arch Dis Child 1973; 48: 404-6.

4 Kattwinkel J, Nearman H S, Fanaroff A A, Katona P G, Klaus $M$ H. Apnea of prematurity: comparative therapeutic effects of cutaneous stimulation and nasal continuous positive airway pressure. J Pediatr 1975; 86: 588-92.

5 Daily W J R, Klaus M, Meyer H B P. Apnea in premature infants: monitoring, incidence, heart rate changes, and an effect of environmental temperature. Pediatrics 1969; 43: $510-8$.

6 Kramer L I, Pierpoint M E. Rocking waterbeds and auditory stimuli to enhance growth of preterm infants. J Pediatr 1976; 88: 297-9.

Correspondence to Dr R A K Jones, Jenny Lind Children's Department, Norfolk and Norwich Hospital, Brunswick Road, Norwich NR1 3SR.

Received 30 June 1981

\section{British Paediatric Association}

\section{Annual meetings}

1982 20-24 April Aviemore Centre, Scotland

1983 12-16 April York University

1984 10-14 April York University

1985 16-20 April York University 